cemoti $\begin{aligned} & \text { Cahiers d'études sur la Méditerranée } \\ & \text { orientale et le monde turco-iranien }\end{aligned}$

$37 \mid 2005$

Jeune recherche II

\title{
Les Turcs meskhètes : des oubliés de l'histoire
}

Sophie TOURNON

\section{OpenEdition}

Journals

Édition électronique

URL : http://journals.openedition.org/cemoti/1576

DOI : $10.4000 /$ cemoti. 1576

ISSN : $1777-5396$

Éditeur

AFEMOTI

Édition imprimée

Date de publication : 1 septembre 2005

ISSN : 0764-9878

Référence électronique

Sophie TOURNON, «Les Turcs meskhètes: des oubliés de l'histoire », Cahiers d'études sur la

Méditerranée orientale et le monde turco-iranien [En ligne], 37 | 2005, mis en ligne le 13 février 2006

consulté le 08 septembre 2020. URL : http://journals.openedition.org/cemoti/1576 ; DOI : https:// doi.org/10.4000/cemoti.1576

Ce document a été généré automatiquement le 8 septembre 2020

Tous droits réservés 


\title{
Les Turcs meskhètes : des oubliés de l'histoire
}

\author{
Sophie TOURNON
}

\section{RÉSUMÉS}

Les Turcs Meskhètes, ou Meskhètes, vivent en diaspora, dispersés dans toute l'URSS. Mais rares sont les familles qui vivent dans leur patrie historique, la Géorgie. L'article traite de l'histoire contemporaine de cette communauté qui n'a plus que leur culture, leur langue, et leur passé de commun. Sous Staline, les Meskhètes subirent le déracinement, l'exil, la liberté surveillée et la punition collective héréditaire. La déportation signa l'impossibilité du retour dans leur pays, et ce jusqu'à présent. Nous retraçons le parcours des principaux mouvements de Meskhètes qui tentèrent de faire valoir leurs droits. Enfin, nous exposons les derniers espoirs qu'ils font reposer sur la Géorgie actuelle et sur les institutions d'Europe. 